\title{
Self-efficacy and optimism as predictors of organizational commitment among bank employees
}

\author{
Akhtar, Saleem \\ Department of Psychology, University of Sargodha, Pakistan (nomi.adil@gmail.com) \\ Ghayas, Saba \\ Department of Psychology, University of Sargodha, Pakistan (saba.ghayas3@gmail.com) \\ Adil, Adnan \\ Department of Psychology, University of Sargodha, Pakistan (livespirit786@yahoo.com)
}

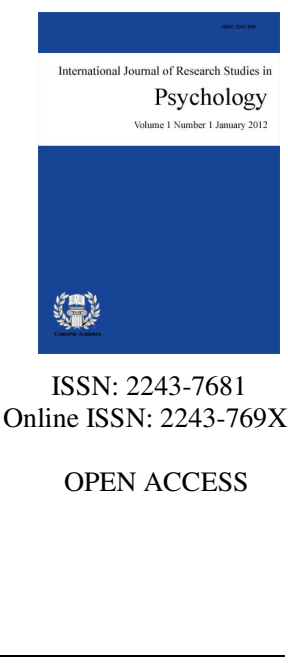

\begin{abstract}
This study explored self efficacy and optimism as the predictors of organizational commitment among bank employees. The data was collected from 150 employees, which consisted of equal number of employees of private $(n=75)$ and semi public sector $(n=75)$ banks of Sargodha. The variables of the study were measured through Organizational Commitment Questionnaire (Mowday, Steers, \& Porter, 1979), General Self Efficacy Scale (Schwarzer \& Jerusalem, 1995) and Optimism Subscale of PsyCap Questionnaire (Luthans, Avolio, Avey, Norman, \& Combs, 2006) respectively. Correlational analyses indicated that self efficacy was positively correlated with optimism and organizational commitment while the optimism and organizational commitment had no correlation. Multiple regressions revealed that self efficacy emerged as significant predictor while the optimism was not significant predictor of organizational commitment. Furthermore it was revealed that employees of private sector banks have higher level of organizational commitment than those of semi public sector banks. It was also explored that professionally qualified employees have higher level of organizational commitment than non-professionally qualified employees. Limitations of the study and suggestions for future research are also discussed.
\end{abstract}

Keywords: self efficacy; optimism; organizational commitment; banking industry; quantitative study 


\section{Self-efficacy and optimism as predictors of organizational commitment among bank employees}

\section{Introduction}

Researchers have highlighted that commitment has a great impact on the successful performance of an organization (Nehmeh, 2009). According to Givens (2008), for developing organizational commitment among employees; managers should try to develop motivation of their employees to do something, and develop the awareness that they do have the ability to achieve the goals. Furthermore, managers should make their employees imagine appealing future outcomes. It reflects that for organizational commitment a person must have the ability to understand his abilities and must have positive ideas about future outcomes. Building on Givens' argument, the present study is an empirical effort to examine self-efficacy: a belief in one's capacities and optimism; the positive attitude towards life as predictors of organizational commitment.

\subsection{Organizational Commitment}

Organizational commitment is a psychological state that binds the individual to organization in which they work (Allen \& Mayer, 1991). Researchers identified three types of commitment: affective commitment is the emotional attachment, identification, and involvement of employees with organization and goals (Mowday et al., 1997; \& Meyer \& Allen, 1993); continuance commitment is the willingness to remain in an organization (Reichers, 1985); and normative commitment is the feeling of person's obligation to organization (Bolon, 1993). Pertinent literature suggests certain individual attributes as significant predictors of organizational commitment. For instance, Luthans and Youssef (2007) found that organizational commitment is positively related with hope, optimism, and resilience (Luthans \& Youssef, 2007) whereas Hurter (2008) and Sinha, Talwar, and Rajpal (2002) found self-efficacy as positive correlate of organizational commitment.

The present study has incorporated self-efficacy and optimism as predictors of organizational commitment since both of these predictors appear to be quite relevant to organizational commitment. A recent study by Cetin (2011) demonstrated the effect of positive psychological capital (hope, self-efficacy, optimism, resilience) on the attitude of organizational commitment and job satisfaction among 213 employees from Ankara, working with different units in ministries and connected institution. The results of this study revealed that optimism and self-efficacy were significant predictors of employee's attitude to organizational commitment. Before we further build the case of self-efficacy and optimism as potential predictors of organizational commitment, the following paragraphs concisely review the nature of these two constructs.

\subsection{Self-Efficacy}

Self-efficacy is a person's feeling about himself that he can perform any work by utilizing his abilities or actions. According to the Bandura (1995), self-efficacy is the belief in one's capabilities in order to perform work in ambiguous or difficult situation. Low self-efficacy promotes negative feelings about one's abilities and responsibility for one's own performance. A high degree of self-efficacy promotes the perception that one is responsible for one's destiny and that one can do what one wants to do.

\subsection{Optimism}

Optimism is a characteristic that is the basis of positive thinking. Optimism reflects one's positive expectations for the future (Carver \& Scheier, 2002). It has been positively correlated with goal-setting and achievement and negatively with goal releasing and acceptance to fate (Lightsey, 1996). 
Literature on the relationship between self-efficacy and organizational commitment supports the notion that self-efficacy is an important determinant of organizational commitment. Sinha, Talwar, and Rajpal (2002) explored the relationship between organizational commitments and self-efficacy among 167 managers of Tata Engineering and Locomotive Company, in India. The results revealed that organizational commitment was positively related with self-efficacy. Similarly, Hurter (2008) found that professional commitment (which is conceptually similar to the organizational commitment) was positively related with self-efficacy. As per the findings of the aforementioned studies, the first hypothesis of the present study suggests that self-efficacy would be a significant predictor of organizational commitment.

Literature on the relationship of optimism and organizational commitment, however, is inconclusive. For instance, Bressler (2006) examined the relationship among hope, optimism, organizational commitment and turnover intentions among United States army reserve soldiers. The results of the study indicated that hope and optimism are positively correlated with affective commitment but not with continuance commitment. Furthermore, higher hope, optimism, affective commitment, and continuance commitment all resulted in correlations with lower turnover intention. Shahnawaz and Jafri (2009) explored psychological capital (which includes psychological capacities of self-efficacy, optimism, resilience, and hope) as a predictor of organizational commitment between public and private sector organization. Results revealed that all psychological capacities; self efficacy, optimism resilience and hope were not predicting organizational commitment in both types of organizations.

Driskell, Copper, and Moran (1994) argued that if people expect failure then they will put less effort into a task. Thus optimistic people who are expecting success in their endeavors are more likely to be high on self-efficacy which in turn significantly predicts organizational commitment. This line of reasoning suggests a moderating role of optimism in the relationship of self-efficacy and organizational commitment. Accordingly, the second hypothesis of the present study suggests that optimism would moderate the relationship between self-efficacy and organizational commitment so that people who are high on optimism would be more committed to their organizations as a function of self-efficacy.

Besides psychological capacities, literature suggests significant impact of some demographic variables on employees' commitment to their organization. For instance, professional qualification of employees and public versus private organizational sector has been found influential in relation to organizational commitment. Professional education usually refers to education for specific professional jobs, which could include law, medicine, teaching (Speck \& Knipe, 2005). Non professional education is not specifically designed for specific profession and it does not require traditional professional education training. Mostly, the people who have non-professional education work directly with other people (Freidson, 2001). Lai et al. (2004) explored that a positive relationship exists between types of qualification and organizational commitment, where professionally qualified employees were found to be higher on organizational commitment. Accordingly, third hypothesis of this study states that employees who have professional education would have higher level of organizational commitment, as compared to those employees who have nonprofessional education.

Employees from public and private sector organizations may also differ in terms of their organizational commitment. The public sector organizations are those where state holdings are more than 50\%, whereas private sector organizations are the part of the economy that is not state controlled, and is run by individuals and companies for profit (D'Souza, 2002). Goulet and Frank (2002) conducted a research to investigate organizational commitment across public and private sectors of different business organization and agencies. They found that private sector workers were the most committed ones while public sector employees have lowest levels of organizational commitment to their organizations. In the light of the aforementioned studies, the fourth hypothesis of present study suggests that employees of the private sector banks would have significantly higher level of organizational commitment, than the employees of semi public sector banks. 


\section{Methodology}

\subsection{Sample}

A convenient sample of 150 bank employees was drawn from various banks of Sargodha city $(N=150)$. Internees in the banks were excluded from the sample. Managers, accountants, cashiers and all others employees whose qualification was master or above masters were taken as participants. The minimum age of the participants was 25 years $(M=37.35$ years, $S D=7.86$ years), and minimum qualification was 16 years of education. The minimum job experience of the participants was 3 years $(M=8.64$ years, $S D=4.51$ years $)$. The sample included both the gender in equal number $(n=75)$. The semi government banks from where the participants were chosen included United bank limited, Habib bank limited, Allied bank limited and Muslim Commercial bank limited $(n=75)$ whereas private sector banks included Faysal bank limited, Meezan Islamic bank limited, Standard Charted bank, and Kasb bank limited $(n=75)$.

\subsection{Instruments}

All the constructs of the present study were measured through psychometrically sound self-report measures. Demographics like age, job experience, gender, education, and employment sector were recorded through demographic sheet. The details of questionnaires used in this study are as follows:

\subsubsection{Organizational Commitment Questionnaire (OCQ)}

Organizational commitment was measured through the Organizational Commitment Questionnaire (OCQ) (Khan, 2008). OCQ consists of nine items and each item is presented with a five point response scale ranging from 'strongly agree' (5) to 'strongly disagree' (1). High score on this scale suggests high levels of organizational commitment and vice versa. Mathieu and Zajac (1990) reported a Cronbach alpha of 0.93 for OCQ.

\subsubsection{General Self Efficacy Scale}

General self efficacy scale (Schwarzer \& Jerusalem, 1995) was used in order to measure self efficacy. Scale consists of ten items and responses are made on a 4-point scale, ranging from 'not at all true (1) to 'exactly true' (4). The responses on all the items are summed up to obtain the composite score where the higher the score higher will be level of self efficacy in the employees. Rimm and Jerusalem (1999) reported Cronbach alpha reliability coefficient of 0.80 for this scale.

\subsubsection{Optimism Subscale of PsyCap Questionnaire}

Optimism Subscale of PsyCap Questionnaire (Luthans, Avolio, Avey, Norman, \& Combs, 2006) was used for measuring optimism. It comprises of six items with a six-point Likert-type scale with categories ranging from 'strongly disagree' (1), to 'strongly agree' (6). High score corresponds to high level of optimism and vice versa. Avey, Patera, and West (2006) reported excellent Cronbach alpha coefficient of reliability 0.92 for this subscale.

\subsection{Procedure}

The formal permission for data collection from the banks of Sargodha was sought from the bank managers. In order to collect the data the employees were personally contacted in their offices. They were briefed about the objectives of the study and were assured of the confidentiality of information that they are going to provide in this research. Informed consent of all the participants was sought after which the aforementioned questionnaires along with demographic sheet were distributed among them. The researchers personally collected back the filled questionnaires and the respondents were thanked for their cooperation and support. 


\section{Results}

The psychometric analysis of the scales used in the present study demonstrated satisfactory levels of internal consistency as Cronbach's alpha ranged from 0.67 to 0.90 . Table 1 indicates that there is significant correlation between optimism and self efficacy $(r=.24, p<.01)$. Self Efficacy and organizational commitment were also significantly correlated $(r=.28, p<.01)$. Optimism and organizational commitment, however, turned out to be not related to each other.

\section{Table 1}

Descriptives, Correlations and Alpha Coefficients of the Scales $(N=150)$

\begin{tabular}{llllllll}
\hline & Variables & $M$ & $S D$ & $\alpha$ & 1 & 2 & 3 \\
\hline 1 & Optimism & 27.9 & 4.09 & .67 & - & $.24^{* *}$ & .06 \\
2 & Self Efficacy & 32.1 & 4.59 & .80 & - & - & $.28^{* *}$ \\
3 & Organizational Commitment & 32.7 & 8.19 & .90 & - & - & - \\
\hline Note. ${ }^{* *} p<.01$
\end{tabular}

The predictive value of self-efficacy and optimism in relation to organizational commitment was assessed through multiple regression analysis. Results indicate that overall the regression model was significant and explained about $8 \%$ of variance in organizational commitment $\left\{R^{2}=.079, F(2,147)=6.28, p=.002\right\}$. Self-efficacy is significant predictor of organizational commitment $(\beta=.28, t=3.47, p=.001)$, whereas optimism did not predict organizational commitment.

Table 2

Predictors of Organizational Commitment $(N=150)$

\begin{tabular}{lcccc}
\hline \multicolumn{1}{c}{ Predictors Variables } & $\mathrm{B}$ & $\mathrm{SE}$ & $\beta$ & $\mathrm{R}^{2}$ \\
\hline Constant & 17.01 & 5.73 & & $.28^{* *}$ \\
Self efficacy & .50 & .14 & - & .079 \\
Optimism & -.02 & .16 & - \\
\hline
\end{tabular}

Note. ${ }^{* *} p<.001, \mathrm{~F}(2,147)=6.28, p=.002$

Employees of public and private sector banks were compared in terms of organizational commitment, self-efficacy, and optimism through independent sample t-test. Table 3 portrayed that there is significant difference in organizational commitment of private $(M=34.02, S D=8.12)$ and semi-public sector $(M=31.37, S D=8.10)$ banks employee. Furthermore it is revealed that private sector banks employees have higher level of organizational commitment than semi public sector banks employees $(t=2.00, p<.05)$.

\section{Table 3}

Differences in Self Efficacy, Optimism and Organizational Commitment among Private Sector and Public Sector Banks Employees $(N=150)$

\begin{tabular}{|c|c|c|c|c|c|c|c|c|}
\hline \multirow{2}{*}{ Variables } & \multicolumn{2}{|c|}{$\begin{array}{l}\text { Private Sector } \\
\quad(n=75)\end{array}$} & \multicolumn{2}{|c|}{$\begin{array}{l}\text { Public Sector } \\
\quad(n=75)\end{array}$} & \multirow{2}{*}{$t(148)$} & \multirow{2}{*}{ Cohen's $d$} & \multicolumn{2}{|c|}{$95 \% \mathrm{CI}$} \\
\hline & $M$ & $S D$ & $M^{(n}$ & $S D$ & & & $L L$ & $U L$ \\
\hline Self-efficacy & 27.16 & 4.07 & 28.17 & 4.12 & 1.12 & 0.14 & -0.78 & 0.51 \\
\hline Optimism & 32.48 & 4.17 & 31.64 & 4.96 & .83 & 0.19 & -0.54 & 0.91 \\
\hline $\begin{array}{l}\text { Organizational } \\
\text { Commitment }\end{array}$ & 34.02 & 8.12 & 31.37 & 8.10 & $2.00 *$ & 0.33 & -0.96 & 1.62 \\
\hline
\end{tabular}

Finally a comparison was made between employees who were professionally qualified with those who were not professionally qualified in terms organizational commitment, self-efficacy, and optimism through independent sample t-test. Table 4 indicates that there is a significant effect of qualification on organizational commitment $(t=$ $2.23, p<.05)$. The mean value revealed that professionally qualified $(M=33.52, S D=7.87)$ employees have higher level of organizational commitment then nonprofessional $(M=30.08, S D=8.74)$ employees Furthermore, it is 
Akhtar, S., Ghayas, S., \& Adil, A.

revealed that professional or non professional qualification had no effect on employees' self-efficacy and optimism.

\section{Table 4}

Differences in Self Efficacy, Optimism and Organizational Commitment among professionally and non professionally qualified employees $(N=150)$

\begin{tabular}{|c|c|c|c|c|c|c|c|c|}
\hline \multirow{2}{*}{ Variables } & \multicolumn{2}{|c|}{$\begin{array}{l}\text { Professionals } \\
\quad(n=75)\end{array}$} & \multicolumn{2}{|c|}{$\begin{array}{c}\text { Nonprofessionals } \\
\quad(n=75)\end{array}$} & \multirow[b]{2}{*}{$t(148)$} & \multirow{2}{*}{ Cohen's $d$} & \multicolumn{2}{|c|}{$95 \%$ CI } \\
\hline & $M$ & $S D$ & $M$ & $S D$ & & & $L L$ & $U L$ \\
\hline Self-efficacy & 32.23 & 4.61 & 31.50 & 4.53 & 0.83 & 0.16 & -0.56 & 0.89 \\
\hline Optimism & 28.15 & 3.70 & 27.05 & 5.12 & 1.41 & 0.25 & -0.46 & 0.96 \\
\hline $\begin{array}{l}\text { Organizational } \\
\text { Commitment }\end{array}$ & 33.52 & 7.87 & 30.08 & 8.74 & $2.23^{*}$ & 0.42 & -0.91 & 1.74 \\
\hline
\end{tabular}

\section{Discussions}

The present study aimed at finding out the relationship among organizational commitment, optimism, and self efficacy in employees of banks. Another important objective of the study was to assess the influence of demographic variables like job experience, type of qualification, and public versus private sector organization on organizational commitment of bank employees.

Primarily it was hypothesized that self-efficacy would significantly predict organizational commitment of employees. Multiple regression analysis was carried out which depicted self efficacy of employees as significant predictors of organizational commitment among employees of banks (see Table 2). The results of Pearson product correlation have also showed that there is significant correlation between the organizational commitment and self efficacy (See Table 1). The results are consistent with Bogler and Somech's study (2004) that found self efficacy as significant predictor of organizational and professional commitment (PC). The results are also supported by the earlier work of Hurter (2008) who found that professional commitment that is conceptually similar to the organizational commitment was positively related with self efficacy. The results also revealed that the employees, who have higher level of self efficacy, have higher level of employee commitment. The demographic analysis of this study portrayed that there is a significant association among different age groups, population groups and income groups. White population group have higher level of self efficacy than combined group in this study.

Self efficacy is the significant predictor of organizational commitment because organizations demand and look for employee's skills, capabilities and working experience. If employees have good skills and capabilities relevant to their assigned work, it may spawn confidence of performing work more efficiently than their counterparts with low self confidence. Consequently, such employees are more likely to be promoted which in turn may enhance their commitment to their organization. An employee with a positive belief about herself/himself becomes confident about her/his assigned work. Showing good performance and having satisfaction that organization is realizing the importance of the individual and his work may lead to higher level of commitment with the organization. This explains why Givens (2008) suggests that leaders should try to increase employees' self efficacy for the enhancement of their organizational commitment.

The second hypothesis of the study was that optimism would be significant predictor of organizational commitment and regression analysis rejected the second hypothesis of the study (see table 2) As the results of present study revealed that optimism is not a significant predictor of organizational commitment among employees of banks which is against the hypothesis of study. The results are consistent with the early study of Shahnawaz and Jafri (2009) who found that optimism is not related with organizational commitment than self efficacy and hope. 
Optimism is not the significant predictor of organizational commitment and both variables are not related with each other among employees of banks. One of the reasons behind the rejection of this hypothesis might be the surrounding environment where people are not supportive and sympathetic towards ones situations and incapability of performing the job e.g. disobeying subordinates, de-motivating peers, autocratic and authoritative seniors. So, we can say that this is not the optimism that predicts our commitment with the work at work place. At times we are not optimistic but still we are performing well, still at the other times we are optimistic yet not performing well. There are lot other factors within control and not within control of an employee to predict his/her commitment with the job. Results further portrayed significant relationship between optimism and self efficacy. Results are consistent with the work of Roux (2010) who found a significant relationship between optimism and self-efficacy, and self-efficacy and work engagement. Similarly findings were also consistent with the recent study conducted by Karademas, Kafetsios, and Sideridis (2007) who found that optimism and self efficacy were positively related with each other.

There is significant relationship between optimism and self efficacy because optimism is the generalized expectancy in which good opposed to bad outcomes occur when confronted with problems across important life domains whereas self efficacy is the belief that one can overcome the obstacles in one's way. Self efficacy is the name of pride, self confidence and trust in one's own capabilities so an efficacious employee will be able to successfully confront the challenges and these mastery experiences may develop an optimistic outlook towards future. According to Seligman (1990), self efficacy leads towards optimism because both can be learned. Interestingly dispositional optimism (type of optimism) is the other name of self efficacy. At present, managers focus on increasing the level of self efficacy and optimism because both of them are leading toward high achievement for organization.

In the present study, it was hypothesized that employees of the private sector banks would have higher level of organizational commitment than the employees of semi public sector. T-test showed significant differences between both categories of banks (semi public sector and private sector) in terms of organizational commitment (see Table 3). It can be explained by comparing semi public and private sector organizations in the context of core approach (three conceptual framework generic, core, and dimensional (Goulet \& Frank, 2002). The core approach suggests that, although some basic similarities exist, but there are fundamental differences among the sectors for example private employees have incentives to manage organizational resources efficiently and effectively because good economic results will return in good rewards and incentives. On the other hand public employees are not sensitive to the efficient use of resources because their rewards are not dependent upon it. It is in the core framework that individual employee differences are emphasized. It also focuses on the behaviors and motivation of employees that is neglected in the semi public sector organizations. According to this approach private sector organization focuses on the employee differences. These organizations reinforce employees on the basis of their work, their skills, and performance. These also focus on the behavior, emotions and feelings of their employees which are very necessary for developing self respect among employees of the organization. One of the most important things which increase the commitment level of private sector employees is the motivation that is provided by their boss, supervisor, or manager through timely feedback, performance based evaluation and promotion, and organizational justice and equity. These motivational facets explain why employees from private sector organization are more committed to their organizations as compared to their counterparts in public sector organizations.

T-test also revealed significant differences in organizational commitment between employees with professional and non professional education as professionally qualified employees were more committed to their organization as compared to their counterparts with non professional education (see Table 4). Reason is that professionally qualified employees are more expert in their relevant field; also they have more trust in their capabilities. Their educational background is similar with their work so they need little rehearsal to familiarize with their assigned work and they can do their jobs more efficiently. Their professional qualification may help them in outperforming their counterparts with non professional education and thus making them more satisfied with their jobs and more committed to their organizations. 


\section{Conclusion}

Overall, the findings of the study are suggestive of the fact that organization should take measures for enhancing the self efficacy of their employees which may become instrumental in retaining a committed work force. Moreover, public sector banks should inculcate the values of private sector banking in order to develop such organizational culture as conducive to improvement of organizational commitment among the employees. The findings of this study also elucidate the necessity of professional qualification for banking employees as professionally qualified work force turned out to be more committed to their organization in comparison with employees having non professional education.

\subsection{Limitations and suggestions for future research}

The sample of the current study was not adequately representative of employees of banking sector as it was limited to a few branches of private and semi public sector banks in Sargodha city only. Future studies should incorporate a broader and more representative sample of banking sector so that the preliminary findings of the present study might be validated. The self report measures of various constructs of and cross sectional design of the present study constitute another limitation of this study as it spawns common method variance. Future research should incorporate multi-method approach towards the operationalization of constructs of interest.

\subsection{Practical implications}

The results of the present study revealed that self-efficacy is an important predictor of employees' commitment to their organization. This implies that self-efficacious employees may constitute a competitive advantage for their organization by virtue of their strong commitment to their organization. Such employees may be more likely to continue their career with their current organizations despite the alluring offers of the competitor firms. Thus, the human resource management practices of selection must undertake the assessment of applicants' self-efficacy which in turn may predict their strong commitment to the organization had they been hired. Furthermore this study indicates that public sector organizations should bring change in their work environment and compensation strategies so that they would be able to develop organizational commitment among their employees. Applications of these findings can bring fruitful change in the managerial settings.

\section{References:}

Avey, J. B., Patera, J. L., \& West, B. J. (2006). Positive psychological capital: A new lens to view absenteeism. Journal of Leadership and Organizational Studies, 13, 42-60. < http://dx.doi.org/10.1177/10717919070130020401>

Bandura, A. (1977). Self efficacy: Toward a unifying theory of behavioral change. Psychological Review, 84, 191-215. <http://dx.doi.org/10.1037/0033-295X.84.2.191>

Bandura, A. (1986). Social foundations of thought and action: A social cognitive theory. Englewood Cliffs, NJ: Prentice-Hall.

Bandura, A. (1995). Self efficacy in changing societies. Cambridge University Press. <http://dx.doi.org/10.1017/CBO9780511527692>

Bogler, R., \& Somech, A. (2004). Influence of teacher empowerment on teachers' organizational commitment, professional commitment and organizational citizenship behavior in schools. Journal of Teaching and Teacher Education, 20, 277-289. <http://dx.doi.org/10.1016/j.tate.2004.02.003>

Bolon, D. S. (1993). Organizational citizenship behavior among hospital employees: A multidimensional analysis involving job satisfaction and organizational commitment. Hospital \& Health Services Administration, 42(2), 221-241.

Bressler, M. E. (2006). Relationship between hope, optimism, organizational commitment, and turnover intention among United States Army Reserve soldiers. Unpublished Masteral theses, University Of Houston-Clear Lake, USA. 
Self-efficacy and optimism as predictors of organizational commitment

Burke, R. J. (1993). Optimism and its benefits. Work-family stress, conflict, coping, and burnout in police officers. Stress Medicine, 9(3), 171-180. <http://dx.doi.org/10.1002/smi.2460090308>

Carver, C., \& Scheier, M. (2002). Optimism. In C. R. Synder \& J. Shane (Eds.), Handbook of positive psychology. New York: Oxford.

Çetin, F. (2011). The effects of the organizational psychological capital on the attitudes of commitment and satisfaction: a public sample in turkey. European Journal of Social Sciences, 5(21), 1-3.

Dignam, J. T., Barrera, M., \& West, S. G. (1986). Occupational stress, social support, and burnout among correctional officers. American Journal of Community Psychology, 14, 177-193. $<$ http://dx.doi.org/10.1007/BF00911820>

Driskell, J. E., Copper, C., \& Moran, A. (1994). Does mental practice enhance performance? Journal of Applied Psychology, 79, 481-492. <http://dx.doi.org/10.1037/0021-9010.79.4.481>

D'Souza, E. (2002). Employment and human resource practices in public sector banks in the nineties. Ahmadabad: Indian Institute of Management.

Ellison, K. W., \& Genz, J. L. (1983). Stress and the police officer. Springfield, I: Charles C. Thomas.

Freidson, E. 2001. Professionalism: The third logic. Chicago: University of Chicago Press.

Ganster, D. C., Fusilier, M. R., \& Mayes, B. T. (1986). Role of social support in the experience of stress at work. Journal of Applied Psychology, 71, 102-110. <http://dx.doi.org/10.1037/0021-9010.71.1.102>

Givens, J. R. (2008). Transformational leadership: the impact on organizational and personal outcomes. Emerging Leadership Journals, 1(1), 4-24.

Glisson, C., \& Durrick, M. (1988). Predictors of job satisfaction and organizational commitment in human service organizations. Administrative Science Quarterly, 33, 61-81. $<$ http://dx.doi.org/10.2307/2392855>

Goulet, L. R. \& Frank, M. L. (2002). Organizational commitment across three sectors: Public, non-profit, and for-profit. Public Personnel Management, 31 (2), 201-210.

Greenberger, E., Goldberg, W. A., Hamil, S., O’Neil, R., \& Payne, C. K. (1989). Contributions of a supportive work environment to parents' well-being and orientation to work. American Journal of Community Psychology, 17(4), 755-783. <http://dx.doi.org/10.1007/BF00922737>

House, J. S. (1981). Work stress and social support. Reading, MA: Addison-Wesley.

House, J. S., \& Wells, J. A. (1978). Occupational stress, social support, and health. Reducing Occupational Stress: Proceedings of a Conference (pp. 8-29). Washington, DC: National Institute of Safety and Health, Publication, 78-140.

Hurter, N. (2008). The role of self efficacy in employee commitment. Unpublished masteral thesis, University of South Africa, South Africa.

Khalid, S., \& Irshad, Z. M. (2010). Job satisfaction among bank employees in Punjab, Pakistan: A comparative study. European Journal of Social Sciences, 17, 1 - 4.

Khan, A. U. (2008). Organizational role stressor and outcomes among health professionals. Unpublished doctoral dissertation, Department of Management Studies, Foundation University Islamabad, Pakistan.

Kopelman, R. E., Brief, A. P., \& Guzzo, R. A. (1990). The role of culture and climate in productivity. In B. Schneider (Ed.), Organizational climate and culture (pp. 282-318). San Francisco: Jossey-Bass.

Lai, G. K., Lv, Y. J., Bao, L. P., \& Li, Z. L. (2004). Predictors of organizational commitment among Chinese employees. Unpublished masteral thesis, Shanghai Academy of Social Sciences, China.

LaRocco, J. M., House, J. S., \& French, J. R. P. (1980). Social support, occupational stress and health. Journal of Health and Social Behavior, 21, 202-218. <http://dx.doi.org/10.2307/2136616>

Lightsey. R. L (1996) .What leads to Wellness? The Role of Psychological Resource in well being. The Journal of Counseling Psychology, 24, 658-735.

Luthans, F., \& Youssef, C. M. (2007). Emerging positive organizational behavior. Journal of Management, 33 , 321-349. <http://dx.doi.org/10.1177/0149206307300814>

Luthans, F., Avey, J. B., Avolio, B. J., Norman, S., \& Combs, G. M. (2006). Psychological capital development: A micro intervention. Journal of Organizational Behavior, 27, 387-393.

$<$ http://dx.doi.org/10.1002/job.373> 
Akhtar, S., Ghayas, S., \& Adil, A.

Martin, S. E. (1990). On the move: The status of women in policing. Washington, DC: The Police Foundation.

Mathieu, J., \& Zajac, D. (1990). A review and meta-analysis of the antecedents, correlates, and consequences of organizational commitment. Psychological Bulletin, 108, 171-94.

<http://dx.doi.org/10.1037/0033-2909.108.2.171>

Mowday, R., \& McDade, T. (1979). Linking behavioral and attitudinal commitment: a longitudinal analysis of job choice and job attitudes. In R. Huseman (Ed.), Academy of management proceedings (pp. 84-88). New York: Academy of Management.

Mowday, R., Steers, R., \& Porter, L. (1979). The measurement of organizational commitment. Journal of Vocational Behavior, 14, 224-247. <http://dx.doi.org/10.1016/0001-8791(79)90072-1>

Nehmeh, R. (2009). What is organizational commitment? Why managers want it in their workforce and if there any cost effective way to secure it? Switzerland: Swiss Management Center.

Pendergrass, V. E., \& Ostrove, N. M. (1984). A survey of stress in women in policing. Journal of Police Science and Administration, 12, 303-309.

Price, B. R. (1985). Sexual integration in American law enforcement. Hard choices in law enforcement. New York: John Jay Press.

Quick, J. C., Murphy, L. R., Hurrell, J. J., Jr., \& Orman, D. (1992). The value of work, the risk of distress, and the power of prevention. In J. C. Quick, L. Murphy, \& J. J. Hurrell, Jr. (Eds.), Stress \& well-being at work: Assessments and interventions for occupational mental health (pp. 3-13). Washington, DC: American Psychological Association. <http://dx.doi.org/10.1037/10116-001>

Reichers, A. (1985). A review and re conceptualization of organizational commitment. The Academy of Management Review,10, 465-476.

Rimm, H., \& Jerusalem, M. (1999). Adaptation and validation of an Estonian version of the General Self-Efficacy Scale (ESES). Anxiety, Stress, and Coping, 12, 329-345. $<$ http://dx.doi.org/10.1080/10615809908250481>

Rousseau, D. M. (1985). Issues of level in organizational research: Multilevel and cross-level perspectives. Research in organizational behavior (pp. 1-38). Greenwich, CT: JAI Press.

Roux, S. (2010). The relationship between authentic leadership, optimism, self-efficacy and work engagement. Unpublished masteral thesis, Stellenbosch University.

Schneider, B. (1990). The climate for service: An application of the climate construct. Organizational climate and culture. San Francisco: Jossey-Bass.

Schwarzer, R., \& Jerusalem, M. (1995). Generalized Self-Efficacy scale. In J. Weinman, S. Wright, \& M. Johnston (Eds.), Measures in health psychology: A user's portfolio. Causal and control beliefs. Windsor, UK: Nfer-Nelson.

Seligman, M. E. P. (1990). Learned optimism. New York: Pocket Books.

Shahnawaz, G. S., \& Jafri, H. S. (2009). Psychological capital as predictors of organizational commitment and organizational citizenship behavior. Journal of the Indian Academy of Applied Psychology, 35, 78-84.

Shinn, M., Wong, N., Simko, P., \& Ortiz-Torres, B. (1989). Promoting the health and wellbeing of working parents: Individual, social, and organizational strategies. American Journal of Community Psychology, 17, 31-56. <http://dx.doi.org/10.1007/BF00931201>

Sinha, P. S., Talwar, T., \& Rajpal, R. (2002). Co-relational study of organizational commitment, self-efficacy and psychological barriers to technological change. Psychologia, 45(3), 176-183. $<$ http://dx.doi.org/10.2117/psysoc.2002.176>

Speck, M. \& Knipe, C. (2005). Why can't we get it right? Designing high-quality professional development for standards-based schools (2nd ed.). Thousand Oaks: Corwin Press Springer.

Tiger, L. (1995). Optimism: The biology of hope, New York: Kodansha.

Wexler, J. G., \& Logan, D. D. (1983). Sources of stress among women police officers. Journal of Police Science and Administration, 11, 46-53.

Yukl, G., \& Van Fleet, D. D. (1992). Theory and research on leadership in organizations. In M. D. Dunnette \& L. M. Hough (Eds.), Handbook of industrial organizational psychology (2nd ed., pp. 147-198). Palo Alto: Consulting Psychologists Press. 